Conclusion* The routine use of cytokeratin immunohistochemistry improves the detection of low volume disease in earlystage cervical cancer, though predominantly ITC, but is expensive.

\section{PROGNOSTIC SIGNIFICANCE OF HPV DNA PRESENCE IN LYMPH NODES IN CERVICAL CANCER PATIENTS - A LONG TERM FOLLOW-UP}

J Sláma*, R Kocián, F Fruhauf, D Fischerova, A Germanova, L Dostálek, D Cibula. First Faculty of Medicine, Charles University and General University Hospital, Department of Gynecology and Obstetrics, Praha 2 - Nové Město

\subsection{6/ijgc-2021-ESGO.49}

Introduction/Background* Metastatic involvement of lymph nodes (LNs) represents one of the most important prognostic parameter in cervical cancer patients. According to the stage it shortens the 5years survival rate by 25-60\%. Moreover, even in low risk group without any risk factor, a part of radicaly treated patiens suffer from relapse of the disease. Presence of HPV DNA in LNs had been therefore studied as a potential marker of unrecognized metastatic involvement.

Methodology Detected were 13 genotypes of high-risk HPV in the lymphatic tissue harwested from patiens who underwent radical hysterectomy with sentinel node biopsy and pelvic lymphadnectomy or paraaortic LN staging. The cytobrush technique was used for perioperative sample collection from the tumour and fresh lymphatic tissue. Only patients with HPV positive tumours who finished their treatment were included and followed.

Result(s)* Out of 119 patients who were included in the study, 93 had available data from their follow-up; 68 underwent radical surgery and 25 were treated by primary definitive radiotherapy. All 19 patients with metastaticaly involved LNs also had HPV in LNs. Another 23 patients had HPV in uninvolved LNs. After a mean follow up of 147 months 19 patients (5 early and 14 localy advanced stages) recurred and died. The majority of them (13/19) had HPV DNA in their LNs, but only 7 had metastases in the LNs at the same time. Only 6 patients $(6.5 \%)$ without HPV DNA in LNs recurred 2 early and 4 localy advanced stages. Negative predictive value for recurrence in cases with HPV negative LNs reached $87.8 \%$ in the whole cohort and $95 \%$ in early stages.

Conclusion* Our pilot study shows that the presence of HPV DNA in LNs is a promising marker of occult metastatic involvement. Its prognostic value should be confirmed in a prospective trial.

Abstract 606 Table 1 Correlation between HPV positivity/ negativity and presence/absence of metastases in LNs

\begin{tabular}{|c|c|c|c|c|}
\hline & & \multicolumn{3}{|l|}{ HPV in LNs } \\
\hline & & Negative & Positive & Together \\
\hline \multirow[t]{3}{*}{ Metastastases in LNs } & Negative & $49(66.2 \%)$ & $25(33.8 \%)$ & $74(100 \%)$ \\
\hline & Positive & 0 & $19(100 \%)$ & $19(100 \%)$ \\
\hline & Together & $49(52.7 \%)$ & $44(47.3 \%)$ & $93(100 \%)$ \\
\hline
\end{tabular}

\section{8 SENTINEL LYMPH NODE MAPPING IN EARLY-STAGE CERVICAL CANCER - A NATIONAL PROSPECTIVE MULTICENTRE STUDY (SENTIREC TRIAL)}

${ }^{1 ; 2 ; 3}$ S Sponholtz* ${ }^{*}{ }^{4 ; 5} \mathrm{O}$ Mogensen, ${ }^{6 ; 7 ; 8} \mathrm{M}$ Hildebrandt, ${ }^{7 ; 9} \mathrm{D}$ Schledermann, ${ }^{10} \mathrm{E}$ Parne ${ }^{1} \mathrm{~A}$ Markauskas, ${ }^{11} \mathrm{~L}$ Froeding, ${ }^{4} \mathrm{~K}$ Fuglsang, ${ }^{6} \mathrm{M}$ Vilstrup, ${ }^{4 ; 5} \mathrm{~S}$ Bjørnholt, ${ }^{3 ; 4 ; 5} \mathrm{P}$ Jensen. 'Odense University Hospital, Department of Gynecology and Obstetrics, Odense c, Denmark; ${ }^{2}$ University of Southern Denmark and Odense University Hospital, Open Patient Data Explorative Network, Odense C, Denmark; ${ }^{3}$ University of Southern Denmark, Department of Clinical Research, Research Unit of Gynecology and Obstetrics, Odense C, Denmark; ${ }^{4}$ Aarhus University Hospital, Department of Gynecology and Obstetrics, Aarhus N, Denmark; ${ }^{5}$ Aarhus University, Institute of Clinical Medicine, Aarhus N, Denmark; ${ }^{6}$ Odense University Hospital, Department of Nuclear Medicine, Odense C, Denmark; ' University of Southern Denmark, Institute of Clinical Research, Odense C, Denmark; ${ }^{8}$ University of Southern Denmark and Odense University Hospital, Center for Innovative Medical Technology, Odense C, Denmark; ${ }^{9}$ Odense University Hospital, Department of Pathology, Odense C, Denmark; ${ }^{10}$ Aarhus University, Department of Public Health, Aarhus C, Denmark; ${ }^{11}$ Copenhagen University Hospital, Department of Gynecology, Kbh Ø, Denmark

\subsection{6/ijgc-2021-ESG0.50}

Introduction/Background* Sentinel lymph node (SLN) mapping is routinely used in many centres to evaluate the lymph node status of women with cervical cancer and small volume disease. However, there is limited evidence regarding the accuracy of SLN mapping for larger cervical tumours. In a national multicentre setting, we evaluated the SLN detection rate and incidence of nodal disease in women with early-stage cervical cancer and investigated the accuracy of SLN mapping and FDG-PET/CT in tumours $>20 \mathrm{~mm}$.

Methodology We prospectively included women with earlystage cervical cancer from March 2017-January 2021 to undergo SLN mapping. Women with tumours $>20 \mathrm{~mm}$ underwent completion pelvic lymphadenectomy and removal of FDG-PET/CT positive nodes. We followed an SLN algorithm with ultrastaging of all SLNs, removal of clinically suspicious lymph nodes and hemi- or full pelvic lymphadenectomy in cases of failed SLN mapping. We determined SLN detection rates, incidence of nodal disease, sensitivity and negative predictive value (NPV) of SLN mapping, and the sensitivity, specificity, NPV, and positive predictive value (PPV) of FDG-PET/ CT.

Result(s)* We included 245 women, and 38 (15.5\%) had nodal metastasis. The SLN detection rate was $96.3 \%(236 /$ $245)$, with $82.0 \%(201 / 245)$ bilateral detection. In a stratified analysis of 103 women with tumours $>20 \mathrm{~mm}, 27$ (26.2\%) had nodal metastases. The sensitivity of SLN mapping adhering to the algorithm was $96.3 \%$ (95\% CI 81.0-99.9\%) and the NPV $98.7 \%$ (95\% CI 93.0-100\%). For FDG-PET/CT imaging the sensitivity was $14.8 \%$ (95\% CI $4.2-33.7 \%$ ), the specificity $85.5 \% \quad(95 \%$ CI $75.6-92.5 \%)$, the NPV $73.9 \%$ (95\% CI 63.4-82.7\%), and the PPV $26.7 \%$ (95\% CI 7.8 $55.1 \%)$.

Conclusion* Our results suggest that SLN mapping is a reliable method in women with early-stage cervical cancer when adhering to an SLN algorithm. However, until the oncological safety is established, we recommend completion pelvic lymphadenectomy in women with tumours $>20 \mathrm{~mm}$. The use of FDG-PET/CT for nodal staging in women with early-stage cervical cancer should be re-evaluated. 